\title{
Classificação das Ações*.
}

\author{
Celso Neves \\ Professor Titular de Direlto Processual Civil da \\ Faculdade de Direito da Universidade de São Paulo.
}

Se é grande a honra de proferir - na esteira de uma tradição mais do que centenária - a Aula Magna com que se inauguram os Cursos Jurídicos desta Academia, neste ano de 1975, maior é a responsabilidade que impõe, para que não se desmereça o sentido desta solenidade, tão cara aos nossos corações como importante na acentuação dos foros de cultura da gente de nossa terra que tem cidadela de pról no Largo de São Francisco.

Para tema desta exposição elegemos a Classificação das Ações, com o objetivo de submeter à consideração dos doutos uma posição que nos parece nova, na doutrina processual, embora parta da natureza da tutela jurídica demandada que tem servido de suporte às modernas CLASSIFICAÇões, tríplice e quíntupla.

Essa nova concepção tem, de tempos para cá, constituido objeto de meditações nossas, de que já há reflexos em palestras que temos proferido, e nos dois livros que, por último, publicamos, sem dar à matéria, entretanto, um tratamento específico, porque não estávamos a cuidar do problema que, neste momento, embora em linhas amplas, procuramos enfrentar.

\footnotetext{
* Aula Inaugural dos Cursos Jurídicos da Faculdade de Direito da Unlversidade de Såo Paulo, proferida a 3 de março de 1975.
} 
Ninguém ignora que a doutrina tradicional, coerente com o conceito imanentista, classificava as ações pelo prisma do direito material, segundo a "res in iudicium deducta" Colocado o assunto no plano privatístico do processo e dominados os termos do problema por tal equacionamento, não se podia recorrer a outros dados, em verdade inatingíveis enquanto a ciência processual não ganhasse a autonomia que, Inodernamente, conquistou.

A Hasse se atribui o primeiro passo, no sentido de conceber-se a ação como figura de processo, já no plano do direito público. A própria posição de SAvigny (Sistema, § 205) não autoriza a pensar-se numa tão ampla revisão de conceitos, embora tenha visto na ação uma relação resultante da lesão do direito, restrita, todavia, a uma simples faculdade do ofendido contra o ofensor. As próprias condições a que subordina a ação - um direito em sí e a respectiva lesão - ainda amarram o tema - pela noção de "actio nata" - ao plano privatístico.

Muther, em sua crítica a Windscheid, apontou - no próprio sistema romano - dois campos distintos, pela afirmação de que, quanto à fórmula, obrigado era o Pretor, como representante da Justiça soberana do Estado; quanto ao direito originário, as partes. Daí a existência de dois direitos diversos, um dos quais pressuposto do outro, pertencentes a esferas diferentes, aquele de natureza privada e este de natureza pública. (\$12)

Paul LABAND (1869) colocou a teoria da pretensão à tutela jurídica a que Plósz (1876), Degenkolb (1877) e WACH (1885) deram desenvolvimento, demonstrando ser de direito público a relação processual.

Era a perspectiva nova que se abria, para a autonomia do direito de ação e a edificação da nova ciência do direito processual que, com a obra fundamental de BüLow, se principiou a erigir. Colocada a ação no plano do direito público, 
a isso deveriam ceder as antigas classificações, decorrentes da concepção imanentista, para dar lugar a esquemas novos, vinculados à natureza jurídica da tutela demandada. A eles correspondem as sistematizações mais amplas que distinguem os processos de conhecimento e executórios, a par dos denominados procedimentos cautelares que, segundo a posição de alguns autores, constituiriam um misto de conhecimento e execução, enquanto outros, negando-lhes executoriedade, os situam entre os procedimentos próprios do processo de conhecimento.

Partindo de tal sistematização, os processos de conhecimento - destinados à solução da lide no plano de juízo foram submetidos a classificações próprias que compreendem os declaratórios, os constitutivos e os condenatórios, a que alguns autores - entre nós Pontes de Miranda - acrescentam os executivos e os mandamentais.

Quanto aos processos executórios, em suas várias modalidades, visam a satisfazer o interesse do exeqüente, sem que neles deixe de estar à frente a realização do direito objetivo, no plano da vontade.

Já os procedimentos cautelares, tendem à segurança, ou da prova, ou da obtenção do efeito juridico pretendido por litigante, ou atual, ou futuro. Daí serem, ou incidentais ou preparatórios.

Essas noções, de trânsito que se pode dizer induvidado, cienotam um princípio fundamental que faz do processo de conhecimento um "prius" do processo executório, bastante acentuado no sistema romano e atenuado pelos juristas da Idade Média que, sob influência de concepções germânicas opostas, criaram a "executio parata", em que o respectivo processo decorria de simples requerimento, sempre "in consequentiam condemnationis", sem desmerecimento do princípio da precedência da cognição, mas relegada a "actio iudicati" do processo romano para casos excepcionais, de completamento da condenação. 
As tentativas de reduzir os termos e atos do processo, exacerbados por influência do procedimento canônico, haviam levado Clemente v a estabelecer o chamado processo sumário, de cognição completa e tramitação abreviada. Permanecia, aí, o princípio da prioridade do conhecimento, em face da execução. Todavia, a parificação à "confessio in iure" do sistema romano - que equivalia à condenação - de certos instrumentos de confissão de dívida perante juízos cartulares, levou a admitir-se a chamada ação executiva que Chrovenda remonta ao processo sumário determinado ou documental, por sua vez derivado do "processus executivus" do direito intermédio.

Mas a evolução, no fio histórico luso brasileiro, sofreu particular derivação, em face da disciplina do Cap. 66, do Livro III, das Ordenações Manuelinas, reiterada no Cap. 25, também do mesmo livro das Filipinas, com a adoção da chamada ação decendiária, a par da ação executiva, "mais próxima do processus executivus italiano", como acentua LiEBMAN, em nota à tradução brasileira das Instituições de CHrovenda.

Não obstante a unificação européia do processo executóijo, persiste o binômio conhecimento-execução, por imperativo da própria natureza das coisas. Lá, opera o juízc; aqui, a realização prática de suas consequiências. Lá, a lide - na terminologia Carneluttiana - é de pretenção resistida; aqui, de pretensão insatisfeita. Lá, opera-se a certeza quanto à "res deducta"; aqui, realiza-se o interesse do litigante.

A diversidade de escopos levara a doutrina a não admitir, por isso, jurisdição no processo executório, em que a atividade do órgão do Estado seria meramente administrativa. Quando se disse jurisdicional o processo de execução, partiu-se de falsa premissa, porque equívoco o próprio sentido do vocábulo jurisdição, dando margem a maiores dúvidas da doutrina, no plano da sua rigorosa conceituação. O próprio sentido etimológico da palavra brigava com tal amplitude de acepção. Dizer 
o direito é próprio e exclusivo do processo de conhecimento. Neste é que, em face de dúvida quanto ao juízo, se diz o direito que incidiu e se soluciona a lide, na medida de sua precomposição pela lei. Sobre isso é que ocorre, como efeito, a coisa julgada. Disso é que - se não basta a sentença aos intentos do litigante - se parte para a execução, como processo consequiencial do processo de conhecimento, naqueles casos em que o interesse do vencedor só pode ser realizado "ex intervallo" Logo, na execução não pode haver atividade jurisdicional, porque essa já se cumpriu, no proceso de conhecimento. O que há é atividade de tutela juris-satisfativa - não jurisdicional - porque o que se quer, nos limites objetivos e subjetivos da coisa julgada, é satisfazer o interesse do litigante.

A coisa julgada aparece, assim, como pressuposto do processo executório, seja nos casos de execução imediata, seja nos casos de execução mediata. Não contradiz a isso a execução provisória, excepcionalmente admitida, em casos determinados, e por isso mesmo, confirmatória da regra geral.

Abrangente de ambas as atividades - jurisdicional e juris-satisfativa - é o dever de tutela jurídica que compete ao Estado, desde que monopolizou os instrumentos de realização da Justiça. Não só dessas duas espécies de atividade que se atribui aos órgãos do Poder Judiciário mas abrangente, também, da atividade "juris-integrativa", a eles igualmente entregue, para o aperfeiçoamento de atos e negócios jurídicos que versem sobre direitos indisponíveis, a que, impropriamente, se tem atribuído a denominação de jurisdição voluntária, não obstante se reconheça que, nela, nem há jurisdição, nem impera a vontade.

A outra conclusão não leva a diversidade de princípios que vigora no processo de conhecimento e no processo executório. Alí, a isonomia, a total imparcialidade do juiz, por cuidar-se de saber quem tem razão; aqui, a heteronomia, a sujeição do vencido a que se dirige a atividade do juiz para satisfazer o vencedor. Alí, a jurisdição; aqui, a juris-satisfação. 
Quando se negava à sentença o poder de criar ou modificar situações jurídicas anteriores, estava-se rente a essa realidade. A sentença, como expressão de atividade jurisdicional, considera o pretérito - a "res in iudicium deducta" - tal como veio para o processo, mediante a postulação do autor ou do autor e do réu, nos casos de juízos dúplices e de reconvenção - e o declara, com a respectiva qualificação legal, decorrente da pre-composição da lide pelo direito que incidiu; solucionando, assim, o conflito de interesses e estabelecendo, sobre ele, a certeza jurídica. Daí a resistência às sentenças denominadas constitutivas.

Essas, precisamente essas, as sentenças objetivamente complexas a que Chrovenda deu atenção, em princípios deste século, e a que Calamandrei dedicou, em 1930, especial estudo. Objetivamente complexas porque a atividade do juiz, tão logo soluciona a lide, desde logo realiza as consequiências práticas da solução adotada. Sentenças em que, na sua unidade formal, se dá uma atividade jurisdicional, a que se segue, imediatamente, uma atividade juris-satisfativa; uma atividade declaratória, própria do processo de conhecimento, e uma atividade satisfazente, própria do processo executório.

Porque é possível o satisfazimento, em certos casos, independentemente da instauração de outro processo; porque se cumulam, num mesmo processo, a pretensão à declaração e a pretenção à satisfação, a sentença que acolhe o pedido, declara o direito do autor, e, desde logo, realiza as conseqüências práticas da declaração.

A meditação dessa realidade levou-nos à convicção de que 0 processo de conhecimento é, estrita e eminentemente, declaratório. Tudo que excede à declaração, já pertence ao plano da execução que pode ocorrer, ou imediatamente, ou "ex intervallo," em ação executória ulterior.

Isso, obviamente, há de ter reflexo no campo da classificação das ações, partindo-se, então, de duas categorias funda- 
mentais: a) ações objetivamente simples; b) ações objetivamente complexas.

As ações de conhecimento, objetivamente simples, são, sempre e apenas, declaratórias. Não tendo outro escopo senão o de estabelecer a certeza jurídica sobre a lide que, objetiva e subjetivamente, delimita o conhecimento do órgão jurisdicional, as ações objetivamente simples visam, sempre, a uma tutela jurídica de natureza estritamente declaratória. $\mathrm{O}$ juízo que nelas se estabelece tem, sempre, por objeto uma situação pretérita, decorrente do conflito de interesses que se desencadeou antes e, pois, fora do processo, já pre-composto pelo direito que incidiu e na medida de cuja pre-composição deve ser solucionado, nos limites da lide. Isto porque não há co-extensão obrigatória entre conflito de interesses e lide, entendida esta no seu conceito eminentemente processual. A dispositividade do pedido pode, porisso, levar ao processo parcial a que se referia CarnelutTI, não abrangente de todo o conflito de interesses, pela delimitação da lide, como consequiência do pedido.

Se a lide é reflexo processual do conflito de interesses qualificados por uma pretensão resistida, a sua solução, no processo, tem natureza declaratória, porque atinente ao que, antes, ocorreu, seja no plano dos fatos, seja do direito sobre eles incidentes, de que resulta a sua pre-composição jurídica.

Esses, em apertada síntese, os dados que nos levam a ver, nos processos de conhecimento objetivamente simples, a via instrumental de prolação de sentença declaratórias, próprias da solução da lide no plano do juízo.

Quanto às ações objetivamente complexas, essas têm escopo mais amplo, por visarem - para além da tutela jurídica declaratória, peculiar ao processo de conhecimento - também às consequiências da declaração, suscetíveis de serem realizadas pelo juiz, na própria sentença. Nesse sentido, objetivamente complexas são as ações tendentes a modificar rela- 
ções jurídicas pre-existentes, sempre que essa modificação possa realizar-se, desde logo, interiormente à sentença, logo após a declaração que reconheça a existência do fato constitutivo da pretensão a que se modifique e, conseqüencialmente, permita a modificação pedida, já no plano de uma atividade que extrapola do juízo, para situar-se no terreno da vontade. Tal atividade não é, portanto, jurisdicional, mas juris-satisfativa, porque visa à realização prática das conseqüências da declaração jurisdicional, esta pressuposto legal daquela.

$\mathrm{O}$ vício que torna anulável o ato jurídico como fato constitutivo da pretensão de anulá-lo - uma vez reconhecida a sua existência e, pois, a incidência da regra do artigo 147 do Código Civil, leva o juiz, no processso que para isso se instaurou, à solução da lide, exaurindo-se, aí, a sua função jurisdicional, se a anulação não foi pedida. Se além do reconhecimento da anulabilidade o pedido é, também, para que se desfaça o ato, passa o juízo a um segundo momento de sua atividade, já então de caráter prático, anulando - executoriamente, portanto $o$ ato indigitado. Neste segundo e sucessivo momento, já não há jurisdição, porque pertencente ele ao plano da realização das consequiências práticas do julgado, em que a atividade, como dissemos, é juris-satisfativa. A sentença, por isso mesmo, é objetivamente complexa, apresentando uma atividade inicial de jurisdição - caracterizada pela declaração sobre o direito que incidiu quanto aos fatos que, precipuamente, determinam essa incidência - e uma subseqüente atividade juris-satisfativa, porque tendente a realizar as consequiências da declaração, tal como pedidas. Conhecimento e execução, portanto, num ato de tutela jurídica formalmente uno.

As ações objetivamente complexas podem ser: ou constitutivas - porque o elemento juris-satisfativo é de constituição ou desconstituição de ato ou negócio jurídico; ou condenatórias - porque, como conseqüência da declaração, impõem a sanção e, normalmente, constituem o título executivo. $\mathrm{Na}$ quelas, como já vimos, a tutela jurídica é, na sua totalidade, 
formalmente una. Já nas condenatórias, há impossibilidade de sê-lo, porque não dispõe o juiz de meios de realizar, ele mesmo, na sentença que profere, o objeto da prestação demandade. Tais açôes visam: ou à entrega de coisa certa ou incerta; ou à execução de obrigações de fazer ou não fazer; ou o pagamento de quantia certa. Em nenhum desses casos há, intuitivamente, possibilidade de a própria sentença realizar o objeto da prestação, a cargo do vencido. Por isso a tutela jurídica, embora de natureza complexa - jurisdicional e jurissatisfativa - não pode ser integral, numa só relação jurídica processual, porque essa, naturalmente, se extingue, no ponto em que deixa de ser possível a atividade do juiz. O completamento, ou provém de prestação do próprio vencido, ou de atividade secundária a substitutiva do órgão do Poder Judiciário. Assim, porque insuscetível de ver realizado, desde logo, todo o seu interesse, o vencedor está adstrito a propor ação executória complementar, "ex intervallo", em que apenas o completamento se pode dar.

Entre as ações objetivamente simples entram, também, as executórias, seja as fundadas em título sentencial, seja as fundadas em título extra-judicial. O que nelas se pede é a satisfação do interesse: no primeiro caso, do ilitigante vencedor no processo de conhecimento objetivamente complexo; no segundo caso, do credor por título extra-judicial dotado de executividade. Numa e noutra hipótese, a ação executória viso, objetivamente, a essa satisfaçãol e a atividade que o juiz desenvolve, no respectivo processo, não é jurisdicional, mas juris-satisfativa.

Não altera esse esquema a circunstância de sujeitar-se o processo executório à suspensividade própria dos embargos do executado, porque estes refletem o exercício da açāo incidental de conhecimento e a atividade que neles desenvolve $o$ órgão do Poder Judiciário é, tipicamente, jurisdicional, podendo enquadrar-se entre as ações objetivamente complexas, consoantemente com a tutela que constitua objeto do pedido do 
embargante. Em outros termos, os embargos do executado, porque, conceitualmente, ação de conhecimento, às características desta se subordinam. Voltados contra a execução, ou contra atos executórios, exigem atividade jurisdicional que pode ter conseqüências executórias próprias e imediatas. Observa-se, a tal propósto, a desconstitutividade da sentença que acolhe os embargos do art. 741 - I, do Código de Processo Civil vigente, para que se perceba o seu conteúdo objetivamente complexo. Já no caso do inciso. II, os embargos refletem o exercício de ação de conhecimento objetivamente simples que se exaure com a declaração, ou da inexigibilidade alegada, ou da exigibilidade do objeto da prestação a que visa o processo executório. Em ambos os casos, a sentença nos parece bastante, em sí só, para realizar o direito objetivo e o interesse do litigante, com a prestação da tutela jurídica reclama$\mathrm{da}$, de natureza jurisdicional, porque o prosseguimento da execução, na segunda hipótese, é consequiência natural da coisa julgada, resultante da decisão da ação de embargos que elimina, nesse caso, a suspensividade deles.

Claro que a natureza objetivamente simples ou objetivainente complexa da ação de embargos depende do pedido que nela se deduza, como em toda e qualquer ação de conhecimento.

Além da pretensão à tutela jurídica de conhecimento e executória, há, ainda, a chamada pretensão cautelar, calcada no interesse, ou à segurança da prova, ou à segurança dos resultados práticos a que tenda a ação, já ajuizada ou em vias de ser proposta. Pode ela, teoricamente, ou ser exercível mediante ação, ou pelo "iter" simplesmente procedimental. Tratada como objeto de ação, o "periculum in mora" entra como elemento do interesse de agir. Regulada procedimentalmente, incluir-se-ia, como acidente, seja nas ações de conhecimento ou preparatórios destas, ou nelas incidentais - seja nas ações de execução, também preparatória ou incidentalmente, tendo por pressuposto, sempre, o "periculum in mora". 
O Código de Processo Civil vigente, em seu Livro III, estabelece a sua disciplina, sob a rubrica Do Processo Cautelar, tratando-a como objeto Das Medidas Cautelares e atribuindolhe natureza simplesmente procedimental: "O procedimento cautelar pode ser instaurado antes ou no curso do processo principal e deste é sempre dependente." (art. 796)

A tutela jurídica cautelar aparece, assim, em nosso sistema de direito positivo, como matéria de simples procedimento, vinculado, ou como "prius," ou como "posterius", ao ajuizamento de determinada ação, subordinando-se, pois, às contingências dessa, pela razão mesma de sua acessoriedade.

Se a ação do processo principal é objetivamente simples, objetivamente simples há de ser o procedimento cautelar, porque restrito, nesse caso, à segurança da prova. Se a ação do processo principal é objetivamente complexa, o procedimento cautelar pode ser, ou objetivamente simples, ou objetivamente complexo, segundo vise, apenas, à segurança da prova, ou vá além e se destine à segurança dos resultados práticos a que tenda a ação.

O procedimento cautelar cabe, ou preparatória, ou incidentalmente, no processo executório que, como vimos, é, sempre, objetivamente simples. Logo, pela sua dependência do processo principal, segue a natureza deste e só pode ser objetivamente simples. Se preparatório, antecipa atos executivos, tendo por pressuposto, sempre, a pretensão à segurança dos resultados práticos da execução; se incidental, "idem" Pensese, nesse particular, no arresto de bens ou no sequestrol de coisa alcançável pela ação executória.

Do exposto resulta que, em termos de classificação das ações segundo a natureza da tutela jurídica demandada, podemos considerar duas categorias fundamentais: a) das ações de conhecimento; b) das ações de execução. Aquelas, comportam subdivisão, podendo ser, ou objetivamente simples, ou 
objetivamente complexas. Estas últimas, as ações executórias, são, sempre, objetivamente simples.

Ainda em termos de classificação, segundo o mesmo critério, as ações objetivamente complexas, ou são constitutivas, ou são condenatórias, segundo a terminologia consagrada pelo moderno direito processual civil. Constitutivas quando a própria sentença pode, desde logo, declarar e executar; condenatórias quando, além da declaração, a sentença só possa executar parcialmente, dependendo o completamento da execução -- que só pode ocorrer "ex intervallo" - do ajuizamento da ação executória - neste caso sempre fundada em título judicial - desde que ocorra o seu pressuposto prático que é o inadimplemento do vencido (Art. 580 do Códigọ de Processo Civil)

A tal linha de raciocínio, as ações que a classificação quíntupla qualifica como executivas, confundir-se-iam com a mandamentais, distinguindo-se destas, apenas, quanto ao destinatário da ordem ou mandado, segundo fosse um particular, ou um agente da autoridade pública, enquadrando-se, ambas, entre as constitutivas, de complementação executória exterior imediata. Isso nos casos em que o mandamento não possa ser concebido como simples efeito secundário da sentença.

$\mathrm{O}$ que pretendemos sustentar, com o que acabamos de expor - repita-se - é que, segundo a natureza da tutela jurídica demandada, as ações podem ser, ou de conhecimento, ou de execução. Nestas, não pode haver pedido objetivamente complexo, só admissível naquelas. Quem exercita ação executória só pode pretender tutela juris-satisfativas; quem exercita ação de conhecimento, pede, sempre, tutela jurisdicional que pode ser cumulada com tutela juris-satisfativa, se o pedido abrange, desde logo, a realização das conseqüências práticas cla declaração, ou suscetíveis de serem alcançadas totalmente, no interior da própria sentença, ou parcialmente dependentes de realização exterior. Exemplos de ações objetivamente complexas, em que a atividade do juiz é jurisdicional e, também, 
juris-satisfativa são as chamadas constitutivas e as condenatórias, aquelas com executividade interior mais completa do que a executividade interior destas últimas.

Importante é que não se classifiquem ações pelo resultado eventual do processo - tal como hoje ocorre - com evidente afetação do princípio da congruência. A ação constitutiva só é constitutiva se julgada procedente; a ação condenatória só é condematória se julgada procedente. Isso, a nosso ver, corrompe a coerência das classificações, permitindo que se exercitem ações constitutivas e condenatórias a que podem não corresponder sentença constitutivas e condenatórias. respectivamente, porque a repulsa ao pedido será, sempre, de natureza declaratória.

Essa incoincidência, entretanto, é impossível nas açōes de conhecimento puras, objetivamente simples, em que a sentença é, sempre declaratória, seja o provimento jurisdicional favorável, ou desfavorável, ao autor.

Tal circunstância é, a nosso ver, da maior importância, mormente quando já verificamos que as chamadas açōes consiitutivas e condenatórias, quando julgadas improcedentes, levam a sentenças de natureza declaratória. Isso revela que a atividade de constituição e de condenação, não pertence ao plano específico das ações de conhecimento, porque apenas ocorre, se e quando a ação for julgada procedente. Implica um "plus" - resultante da declaração jurisdicional que soluciona a lide de pretensão resistida - com ubicação no plano da lide de pretensão insatisfeita, para adotarmos a terminologia de CARnelutti. Logo, constitui matéria própria da ação executória, pragmaticamente inserida em processo de conhecimento.

Da essência do processo de conhecimento é, só, a declaração. Essencial ao processo executório é, apenas, a satisfação. Com isso extremam-se os lindes próprios de um e outro e demonstra-se que, segundo a natureza da tutela pretendida, as ações, ou são de conhecimento, cu são de execução, com a consequiência de não haver jurisdição nestas últimas. 
À luz dessas ponderações, chegamos à seguinte classificação das ações, fundamentalmente binária, tendo por base a tutela jurídica demandada:

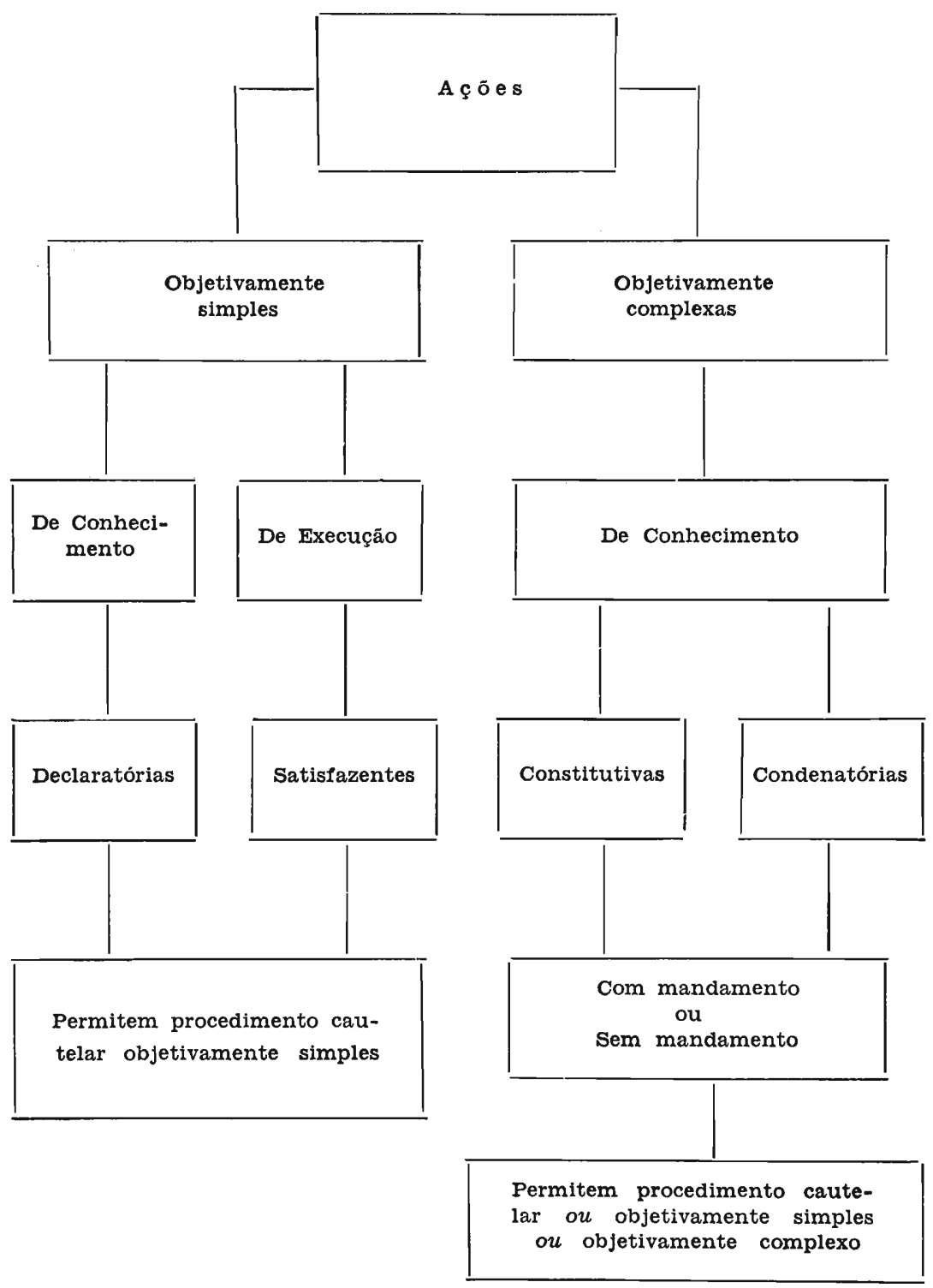


Minhas Senhoras e Meus Senhores.

Perdoem-nos se o tratamento de um tema eminentemente técnico, não nos tenha permitido uma dissertação leve $e$ agradável, mas estamos certos de que compreenderão o sentido e a destinação de uma aula inaugural, em uma escola que, pelas suas tradições veneráveis, tem as mais altas responsabilidades, no plano do civismo e da cultura em nosso país. Que as suas atividades, no ano letivo que ora se inicia, a isso correspondam, são os nossos votos. 